\title{
TRANSFERRING TO EMERGENCY REMOTE TEACHING: OPPORTUNITY, CHALLENGES, AND RISKS
}

\author{
Mohammad A. N. Al-Azawi \\ Assist. Prof. Dr., Oman College of Management and Technology, Oman \\ mohd.alazawi@omancollege.edu.om
}

\begin{abstract}
This study sheds light on risks pertaining to interruptions disturbing the continuity of the course of higher academic education and the inability of students to attend regular classes for any reasons that may occur. Further enquiry is conducted as to how the institution can be equipped in lieu of the occurrence of such incidents. As there is some kind of ambiguity between Emergency Remote Teaching (ERT), distance learning, and e-learning; the study attempts to provide detailed information about e-learning mechanisms, dimensions, and strategies. Furthermore, it links them with emergency remote teaching (ERT) to give a clearer picture of the possible transition strategies to ERT. The focus is on presenting a discursive analysis of the best practices that need to be considered when transitioning to ERT and highlighting the challenges and risks that one may face during the switching process. Parts of the hypothesis presented in this research are supported by empirical results obtained from collecting responses and data from various stakeholders.
\end{abstract}

Keywords: Emergency Remote Teaching, ERT, E-learning, Crisis, Education.

\section{INTRODUCTION}

The circumstances and conditions that require switching to ERT have so far been temporary and the period is not predetermined. Every educational institution must be prepared for such a transition at any given time. In order to do so, one must start by identifying the risks of study interruption, assess the risks which could have a high impact factor and accordingly set up a comprehensive mitigation plan. Although the current global Covid-19 pandemic may be the main reason of instigating an enquiry into this issue, this interruption has been identified in many educational institutions as one of the risks that not only requires due attention and but also one that needs the development of comprehensive plans to deal with it. Emergency remote teaching (ERT) can be understood as the process of switching from traditional education to electronic education in a short time and with limited capabilities.

Educational institutions that were not ready for such risks may face difficulties in switching to e-learning or distance learning as a result of the fact that this change is not just a change in the teaching methods but also one that materialises in the teaching system itself.

There may be many factors that may help and facilitate this transition, such as the availability of the necessary technologies or electronic culture. However, there are many difficulties that accompany the transition process. Two major concerns towards electronic education system are lack of necessary expertise and the inappropriateness of the course content which need to be analysed.

To get a clear idea about the opportunities and challenges accompanying the switch to ERT, we need first to understand the difference between the two systems, i.e. traditional (physical) system and remote (electronic) system. Therefore, a thorough discussion about e-learning system and its various aspects, dimensions and strategies is presented in this research. 
The hypothesis of the research is supported by empirical results obtained from collecting responses from the students and the academic staff. The data was collected anonymously from about 350 participants. The same data collection has been done twice. Once immediately after two weeks from the transfer to ERT and the second time after the final exam. The change in responses has been analysed carefully and used to support and justify the theoretical claims put forth in this study.

The second section of the paper contains detailed information about online learning and distance learning. Aspects, such as types, dimensions, and differences between the various types of such programmes are also discussed. The third section provides information about emergency remote teaching (ERT) and compares it to online teaching. The opportunities, challenges and risks associated with the transition to ERT are discussed in detail in the fourth section. The analysis is supported by some empirical results obtained from collecting data directly from some of the stakeholders. Finally, a conclusion is derived in the last part of the research.

\section{ONLINE AND DISTANCE LEARNING}

Online teaching is part of distance learning which refers to any teaching that does not take place in a physical classroom. Distance learning has passed through several phases, starting from correspondence courses where teaching materials were sent via regular mail with very little interaction. The second phase was telecourses, in which course contents are delivered via radio or TV. CD-ROM was utilised later on to equip students with course contents to be used with a standalone computer. The advancement in the information and communication technology (ICT) made it easy to create classes that support digital interaction between the instructor and the students.

Before the smartphone era, mobile learning was essentially used to transfer course content and for online classroom interactions. In the current times, smartphones have become the primary device used as they contain most of the capabilities of a regular computer and can be used to access modern e-learning services such as e-learning management systems and virtual classes (Stern, 2018).

Online teaching or electronic learning, usually referred to as e-learning, is not a new trend. This practice started as early as the 1960s. The first computer-enabled virtual classroom was created in the University of Illinois where students were able to access learning resources while listening to remotely broadcasted lectures (Johnson, Hewapathirana, \& Bowen, 2019). Several authors have defined online learning in a slightly different manner but the general definition could be stated as the use of ICT and other related technologies in delivering lectures and assessment (Nycz \& Cohen, 2007). Although this definition is widely used, it is not an accurate definition as it neglects other e-learning dimensions and focuses only on the physical location and the use of ICT in teaching. E-learning definitions should consider some other dimensions as well. Some of these have been listed out in the next section.

\subsection{Dimensions of E-Learning}

It seems simplistic to claim that e-learning's sole purpose is to facilitate the delivery of lectures. Some crucial dimensions that need to be considered in any successful e-learning system have been elucidated upon. The list is as follows:

1- Technology: The availability of appropriate technology is essential for any e-learning process. Technologies such as a reliable internet connection, suitable hardware, and necessary software are major factors of the e-learning system, but they are not the only factors.

2- Well-designed course contents (Lubis, Ritonga, Hia, \& Nasution, 2020): Developing content suitable for elearning is a vital factor as not all the content developed for regular or physical classes is suitable for elearning. Learning theories should be considered when designing the subject matter. For instance, developing a course structure for pedagogical learning is different from developing materials for andrological learning. In pedagogical learning, the role of the instructor will be more so that of a knowledge presenter, while in andrological learning, the instructor will function as a facilitator. Therefore, developing content for the same course should be different based on the learning theory.

3- Well-trained instructors: As the role of the instructor in e-learning is not limited to presenting the course material, instructors who undertake online teaching require skills in a variety of fields. For instance, the instructor should be aware of the differences between traditional teaching and online teaching and should have a deep understanding of these differences. In addition to that, the instructor should have a good knowledge of the technology used for this purpose and must be able to solve the minor issues that arise for him or his students during the process. The capability to design course material and assessments suitable for this kind of teaching is another important skill the instructor needs to be familiar with. 
4- Well-prepared students: Preparing the student for this type of teaching is also a major challenge that must be taken into consideration during the educational process. The student must be familiar with the technology used and must be well-trained to use it. By doing this, one variable can be removed from the equation and most of the efforts can be directed towards an effective educational process. Training the student about his/her conduct, online behaviour, academic integrity and making him familiar with the assessment process is just about as important as the training on using the technology itself. This can be achieved by advising and guiding the student to follow the due procedures related to the field.

5- Suitable assessment method: The assessment method is a crucial issue in higher education applicable to both general and online teaching. Most of the assessment methods that are used in traditional teaching in physical classes are not suitable for online teaching for many reasons. Firstly, the assessor should consider the availability of the internet, course content and even the availability of experts in the field to help the student successfully take the exam or the assignment. Therefore, the assessment method should be chosen and designed carefully to be fair and should fulfil the objectives of the course.

6- Academic support services for students and instructors: The availability of academic support, services and tools is another important aspect of the educational process. Services such as e-library, training and webinars, software and academic advising are important. They must be provided to the student in order for him/her to accomplish a successful educational programme that enables one to achieve the goals of the programmes they study.

7- Academic Quality: No educational programme can succeed without adequate quality assurance standards. Thus, all educational institutions must develop appropriate standards, bylaws, policies, and procedures to ensure the academic quality of the educational process. The institution can benefit from publications issued by some specialised international societies or associations, such as The European Association for Quality Assurance in Higher Education (ENQA).

\subsection{Synchronous or Asynchronous Classes}

The debate regarding what type of e-learning is better is not valid as selecting the appropriate type depends on the need and the learning theory e.g. pedagogical or andragogical. Classes in e-learning can be classified mainly into synchronous and asynchronous classes and sometimes a hybrid type is considered as well (Basilaia \& Kvavadze, 2020).

Synchronous classes have a lot of similarity to physical classes as there should be a class schedule, compulsory attendance and a predefined timeframe. In this category, lectures are delivered where the instructor and the students are attending a virtual meeting. The instructor explains the topics and shares slides and other course contents. The student can interact with the instructor and ask questions. The instructor, in his turn, can ask the students to participate. These kinds of classes should include chat rooms rather than discussion boards for collaboration. Synchronous classes are instructor centred as the instructor is the source of knowledge and responsible for preparing the contents and explaining them.

Based on the above description, it is clear that synchronous e-learning class is more applicable to pedagogical learning and is more suitable for schools and early stages of undergraduate studies (Hrastinski, 2007).

On the other hand, asynchronous online classes have little similarity to physical classrooms as there are no schedules, timeframes, direct discussions or interaction. These classes can be used with andragogical learning as it is more learner-centred than subject or instructor-centred. The instructor can share the lectures with the students using multimedia formats such as videos and voice. Additionally, the instructor can share course contents such as slides and books. It is the responsibility of the student to study the course contents and to search for further resources. Discussion boards are useful here as students can interact and collaborate with each other and with the instructor by posting their questions and discussion topics of interest (Girard, Willoughby, \& Berg, 2007).

The advancement in modern-day technology has made it possible to have a third type of online class, namely the hybrid classes which have the advantages of the two aforementioned types. In this type, the lecture is given in a meeting attended by the instructor and the students, planned at a pre-specified time and they can collaborate with each other during the lecture time. The lecture is then recorded and the students who were unable to attend can watch the recording and post their questions to the discussion board later.

\section{EMERGENCY REMOTE TEACHING (ERT)}

The term emergency remote teaching has started being used recently in many publications due to the pandemic and the lockdown circumstances. The term emergency remote teaching is not the same as e- 
learning or online teaching (Bozkurt \& Sharma, 2020), (Affouneh, Salha, \& Khlaif, 2020), (Hodges, Moore, Lockee, Trust, \& Bond, 2020). Emergency remote teaching is the process of transferring teaching from physical classes to virtual classes instantaneously and temporarily.

Emergency remote teaching differs from e-learning because it happens without preplanning and for this reason, the word emergency was used. How is emergency remote teaching different from e-learning? Elearning usually needs a lot of preparation, planning and prior training, while in emergency remote education, some of these requirements may not be available as the shift from physical classes to virtual classes may need to be done promptly.

Corona pandemic may have highlighted this need. but in fact, the educational institution should be ready for such kind of risks which might be caused by other reasons such as weather conditions and other such circumstances that require the institution to be closed for a certain period. Some educational institutions did not identify interruption of conducting regular classes as one of the major risks that needs to be mitigated, studied and prepares for, therefore, they faced difficulties in shifting their teaching formats to virtual from the followed physical format.

The process of switching from traditional education to e-learning is not just a transition from giving lectures in a physical classroom to giving them remotely via the internet. This misconception in understanding may cause some educational institutions to struggle and even fail to manage the process successfully. In fact, it is a process of moving from one academic system to another and satisfying the new system's characteristics mentioned above. E-learning does not solely depend on the availability of technology. There are some other factors that need to be considered, starting from designing the study materials, building the skills of the instructors and students and ending with the assessment.

\section{RESOURCES, CHALLENGES AND RISKS}

This section provides details on the various resources that the institution can use for transferring classes from traditional classes to electronic classes. In addition, the challenges that might hinder the efforts of the institution during the process have been discussed. Finally, the risks associated with this transfer have also been elucidated upon.

\subsection{Resources}

Several resources can be utilised to facilitate transferring classes from physical to virtual. Some of them are as follows:

\subsubsection{Infrastructure:}

Well-established electronic infrastructure is essential in each educational institution and is considered one of the key requirements that any such institution must meet. The vital electronic infrastructure components are:

1- Student Information System (SIS): Every institution should have an SIS which can be used to register students, follow up their attendance and publish results and marks amongst several other functions. This system makes it easy for the institution to manage the mentioned essential processes remotely.

2- Email system: All institutions should provide each student with an email address to communicate with the instructors and the institution at large. These emails are generally integrated with other electronic systems and services such as e-learning management systems and libraries. Nowadays, integrated educational platforms such as G Suite and Microsoft Office365 have become more easily available and can be used by Educational Institutions.

3- E-learning management system (ELMS): In the last few decades, ELMS has become known to most educational institutions and at the present time, one may not find an educational institution devoid of this system. ELMS is widely used as a supporting system for traditional classes where it is used to share the course content and for giving homework and assignments. In ELMS, each physical class should have a virtual class corresponding to it and accessible by the instructor and the students. Therefore, the existence of ELMS shall make the transfer to ERT an easy task.

\subsubsection{Well-trained people}

All students and instructors need to be made aware of how to use the systems and get familiar with them so that they can use them from home without serious difficulties.

\subsection{Challenges}

There are many challenges that accompany the process of switching to emergency remote teaching which 
need to be studied and considered, including:

\subsubsection{Infrastructure}

The lack or unavailability of the necessary infrastructure that the student and Instructor need, can be considered as one of the major challenges. Although this infrastructure is available in the educational institution and considered as one of the opportunities that can be taken advantage of in the process of transition to ERT, the possibility of not having the appropriate infrastructure for the student or teacher at home may be considered one of the major challenges that hinders the process. Usually, the student can use the infrastructure available at some institutions that provide time slots for free access and open laboratories that the student can use to enter the ELMS.

As was discussed earlier, the availability of suitable infrastructure can be one of the main challenges in the switching process. Unavailability might occur due to several reasons, one of them being that the students are not ready for such kind of learning as they used to use the facilities provided to them by the institution. From the first survey, it was found that 97 per cent of the students do not have problems with the availability of computers or smartphones, though, 77 per cent of them used smartphones while attending classes and taking the exams. However, around 41 per cent of the students suffered from difficulties arising due to a lack of the availability of an internet connection. In the second survey, students seemed to be more aware of the process and managed to have appropriate infrastructure for it. Results from the second survey showcased an increase in the number of students who had access to a computer or smartphone to 100 per cent. The number of students using a computer also increased to 33 per cent. Additionally, the number of students who had access to a suitable internet connection increased from 59 per cent to 78 per cent.

\subsubsection{Reluctance or Resistance to Change}

The reluctance or resistance to change is one of the most dangerous challenges as people usually fear the unknown. This reluctance has many reasons, including psychological, financial and habitual factors. (Yılmaz \& Kılıçoğlu, 2013) (Pardo del Val \& Martínez Fuentes, 2003). Students may be concerned about their academic progress or the time needed to learn new techniques that can be used for studying and preparation. On the other hand, the instructors may feel apprehensive due to the additional effort that would be required by them in preparing content appropriate for the new system.

This subject has been measured by asking the students to answer what options they prefer in case of work suspension. There were two options for them to choose from; either to suspend the study and postpone all the activities or to switch to ERT. In the first survey, most of the students were unhappy with ERT, as 58 per cent of them preferred postponing the study and 42 per cent accepted ERT. In the second survey and after the students tried ERT, 83 per cent of the surveyed students were happy with ERT. This implies that at the beginning the students were afraid of ERT as it was unknown to them. After trying ERT, most of the students were happy with choosing ERT over study suspension.

\subsubsection{Suitability of the Courses and their Contents}

Online lecturing may not be suitable for all subjects taught in traditional methods, such as subjects requiring laboratories and infrastructure for practical training. Therefore, the nature of the subject may be considered as an obstacle that limits the possibility of transferring to distance teaching. In addition, the nature of the content taught in regular classes may not be fully compatible with that required by the virtual class. Therefore, due modifications and updates need to be made to fit the nature of the new teaching method.

\subsubsection{Assessment}

The assessment method is one of the major challenges that must be taken into consideration, as transferring to e-learning requires changing the style and method of assessment from the regular method to an assessment method that adapts to the Internet and the open book strategies. The skills and experience required may not be available for most teachers in this field. This may result in the lack of a fair and appropriate evaluation that fairly distinguishes the levels of various students. Often, the appropriateness and fairness of the tests are measured by some statistical values calculated for the grades of the students, such as class average and deviation. If the class average is very high or very low or the deviation is too low, then the assessment method is not appropriate and needs to be revised.

\subsection{Risks}

The process of the transformation to e-learning may be accompanied by many risks, including those related to technology and people. Major risks related to technology include the failure of servers or systems, the interruption of internet signals and the failure of devices such as computers and smartphones. These risks 
can often be solved easily by providing users with a hotline that must always be available to solve technical problems.

Risks attributing to people can emerge in many ways, including compromises occurring in academic integrity, attendance and cheating.

Academic integrity of the student or instructor must be carefully considered and mitigated. If there is no direct follow-up with the student or sometimes even with the instructor, it may result in poor follow up of academic norms and an overall failure in achieving the required learning outcomes. Attendance is also another risk. The student may not attend class or leave the computer on and go somewhere else. Academic misconduct due to lack of invigilation during exams or assignments is a major risk that can be overcome by designing a suitable exam or assignment.

\section{CONCLUSION}

This research studied emergency remote teaching and its various aspects. Furthermore, it highlighted the main resources that can be utilised to make the transformation from traditional to virtual teaching easier. It also presented a purview of the challenges associated with the switching process. To enrich the study with the necessary background, details about online teaching have been presented as well. The difference between ERT and e-learning has been studied and a comprehensive comparison has been showcased.

On basis of the study conducted, it is recommended that all educational institutions should consider the risk of study interruption as one with a high impact factor and that they should set comprehensive plans to mitigate it. The planning should include, amongst many other factors, training the staff on how to be ready for such incidents. The training not only includes preparation on how to use the e-learning management systems but also lays emphasis on preparing unique course content and assessments suitable for ERT.

\section{REFERENCE LIST}

Affouneh, S., Salha, S., \& Khlaif, Z. N. (2020). Designing Quality E-Learning Environments for Emergency Remote Teaching in Coronavirus Crisis. Interdisciplinary Journal of Virtual Learning in Medical Sciences, 11(2), 1-3.

Basilaia, G., \& Kvavadze, D. (2020). Transition to Online Education in Schools during a SARS-CoV-2 Coronavirus (COVID-19) Pandemic in Georgia. Pedagogical Research, 5(4). https://doi.org/10.29333/pr/7937

Bozkurt, A., \& Sharma, R. C. (2020). Emergency remote teaching in a time of global crisis due to CoronaVirus pandemic. Asian Journal of Distance Education, 15(1), i-vi.

Girard, J., Willoughby, L., \& Berg, K. (2007). Video, Voice, and Virtual Collaboration: The 3V's of Asynchronous Education. In N. Buzzetto-Hollywood (Ed.), Principles of Effective Online Teaching. California: Informing Science Press.

Hodges, A. C., Moore, S., Lockee, B., Trust, T., \& Bond, A. (2020). The Difference Between Emergency Remote Teaching and Online Learning. Retrieved June 20, 2020, from https://er.educause.edu/articles/2020/3/the-difference-between-emergency-remote-teaching-andonline-learning

Hrastinski, S. (2007). Dimensions of Synchronous Online Education. In N. Buzzetto-Hollywood (Ed.), Principles of Effective Online Teaching (pp. 107-119). California: Informing Science Press.

Johnson, K. R., Hewapathirana, G. I., \& Bowen, M. M. (2019). Faculty Development for Online Teaching. In Handbook of Research on Virtual Training and Mentoring of Online Instructors (J. S. Keen, pp. 40-55). https://doi.org/10.4018/978-1-5225-6322-8.ch003

Lubis, A., Ritonga, A., Hia, Y., \& Nasution, A. A. (2020). Online Learning Design at Higher Education: An Example from Mathematics Classroom. Journal of Physics: Conference Series, 1462(1). https://doi.org/10.1088/1742-6596/1462/1/012004

Nycz, M., \& Cohen, E. B. (2007). Basics for Understanding E-Learning. In N. Buzzetto-Hollywood (Ed.), Principles of Effective Online Teaching (pp. 1-17). California: Informing Science Press.

Pardo del Val, M., \& Martínez Fuentes, C. (2003). Resistance to change: a literature review and empirical 
study. Management Decision, 41(2), 148-155. https://doi.org/10.1108/00251740310457597

Stern, J. (2018). Introduction to Online Teaching and Learning. International Journal of Science Education, (3), 1-10. https://doi.org/10.1002/9781118784235.eeltv06b

Yılmaz, D., \& Kılıçoğlu, G. (2013). Resistance to change and ways of reducing resistance in educational organizations. European Journal of Research on Education, 1(c), 14-21. 